\title{
A Comparative Analysis toward Two Famous Smart- Tourism by Integrated Dynamic-Programming \& Project Appraisal Model
}

\author{
Tianhang Huang ${ }^{1 *}$ and Nan Zhang ${ }^{2}$ \\ ${ }^{1}$ School of Public Policy and Management, Univeristy of Chinese Academy of Sciences, Beijing, China. \\ ${ }^{2}$ School of Public Policy and Management, Tsinghua Univeristy, Beijing, China. \\ ${ }^{*}$ Corresponding author
}

\begin{abstract}
The purpose of this study is aimed to construct a comprehensive theoretical framework for explaining the characteristics of different Smart Tourism Projects' Designing and Developing, and finding the best practice model in this booming area. Based on the three stages of $R \& D$ project pipeline of dynamic-programming model, and Project Appraisal Model (PAM), the research framework of the study focuses on the three dimensions, economic and scoring values: energy benefits, consumer savings and societal factors. Furthermore, for enhancing the explanation of the framework, five example types of R\&D uncertainty from (Huchzermeier \& Loch 2001) were considered: market payoffs, project budgets, product performance, market requirements, and project schedules. For examining the value of the framework, this paper analyzes the Difference of two Smart Tourism projects in two famous Chinese scenic regions, Huang Mountain and Tai Mountain. Conclusion, our focus was set at discovering the difference between the processes of those two Smart Tourism systems based on the integrated theoretical framework.
\end{abstract}

Keywords-smart tourism; $R \& D$ project;dynamic-programming model; project appraisal model; huang mountain; tai mountain

\section{INTRODUCTION}

The original intention for raising "Smart Tourism" is to comprehensively use modern information technology, which is not only an efficient approach to enhance overall management level of the scenic spots but also an important means to further improve operating methods and innovate management mechanism, and to boost management and service capability in resources and environment protection, planning and construction management, sightseeing organizational management and public service, security assurance for tourists, prevention and reduction of natural disasters, and response to emergency so as to reduce administrative costs, increase management efficiency, innovate management system and enhance comprehensive management level, promote sound development of the cause of the scenic spots and offer better service for the general public. However, at present, a consensus mode regarding how to make a planning and perform construction and how to better meet the needs of the management of the Management Council and common tourists are still unavailable. The core of building Smart Tourism is integrating sensor network, networking, the Internet, and spatial information technology to achieve comprehensive, real- time, interactive, fine, sustainable of scenic management (Dang etl. 2011). However, although high level investment on Smart Tourism in China, face to the question that how to build Smart Tourism, The theoretical research still lack to our knowledge.

Based on the generalization of development history of "Smart Tourism" in China and taking Huang Mountain and Tai Mountain as case study (the Management Council of Tai Mountain, 2011; the Management Council of Huang Mountain, 2011), this study makes a research on the primary procedures and the key technical means for building the "Smart Tourism", and compares similarities and differences between the construction of "Smart Tourism" in Huang Mountain and Tai Mountain, and thereby representing the primary achievements on building the "Smart Tourism" in China and offering reference for researches on the construction of "Smart Tourism”.

\section{RESEARCH MODEL}

\section{A. Introduction of Research Model}

As referring to the research of (Chan \& Nickerson 2007), we believe that different possibilities for the overall project construction of "Smart Tourism" depend on three stages: (1) Research (2) Development (3) Commercialization. This study will discuss how the "Smart Tourism" breaks in China based on the case studies of "Smart Tai Mountain" and "Smart Huang Mountain". And how the administers of the scenic regions adjust these projects dynamically by the respective influencing factors. According to the features of Chinese Smart Tourism, the theoretical framework of the study is shown in Figure I.

The template is used to format your paper and style the text. All margins, column widths, line spaces, and text fonts are prescribed; please do not alter them. You may note peculiarities. For example, the head margin in this template measures proportionately more than is customary. This measurement and others are deliberate, using specifications that anticipate your paper as one part of the entire proceedings, and not as an independent document. Please do not revise any of the current designations. Firstly, in the research stage, According to the three-stage model regarding project research and development and commercialization (Chan \& Nickerson 2007) as well as the Project Appraisal Model (PAM), which has by far been the 
most widely discussed among all the related approach for estimating the relative merits of $R \& D$ programs (Silverman,1981), we introduce the parameter of energy benefits(According to the characteristics of development of "Smart Tourism", the parameter comprises: Scenic Region Time, Project budgets, Scenic Region Heterogeneity, System functional analyzing, Provisions software performance, Data management ability. These six factors make explanations on the influencing factors faced by "Smart Tourism" during the research stage. As referring to("Three-Dimensional Tai Mountain” GIS System Software Development Requirement Specification and "Smart Huang Mountain" Overall Planning Formulation 2011-2015, the author participates in the two projects and obtains the major documents regarding the research, development, and marketizatioin of the overall project from the management committees of the scenic regions of Huang Mountain and Tai Mountain.

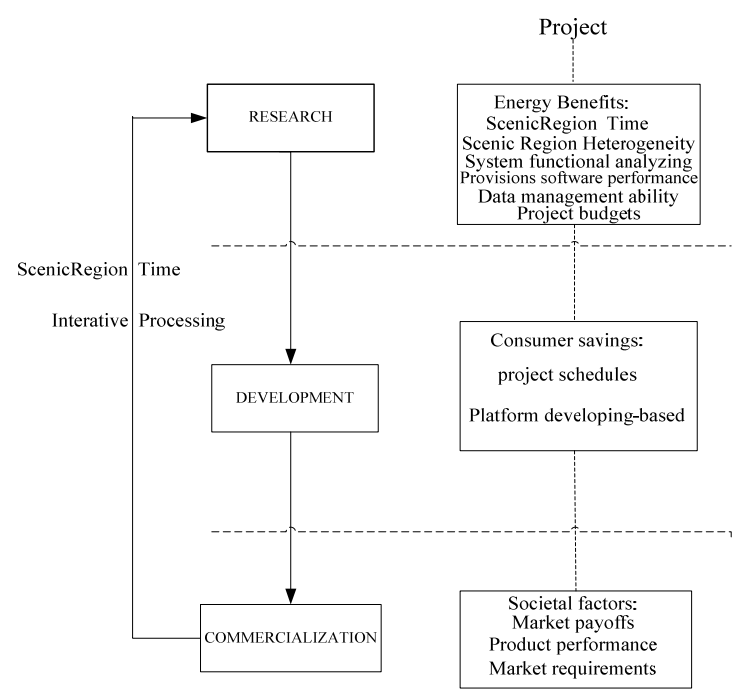

FIGURE I. THEORETICAL FRAMEWORK OF THE STUDYRESEARCH

The parameter of energy benefits is introduced, and it originates from Project Appraisal Model (PAM) (Silverman, 1981). The parameter is used for R\&D planning of Department of Energy in the original text. The role of the parameter exerted on the research process for the Smart Tourism is also recognized by this study, whereas specific parameter is adjusted.

\section{(1) Scenic Region Time}

The "smart scenic region" has its timeliness, because the process of design and development has precedence relationship. The whole process of the construction of "smart scenic region" is an iterative procedure in which new solutions continuously replace the original old ones.

\section{(2) Scenic Region Heterogeneity}

At present, there are multiple methods for classifying tourist attractions, which are divided into natural landscape and human landscape according to the attractions on which they depend. The peculiarity of the scenic regions determines certain functions and certain degree of development for the construction of "Smart Tourism".

\section{(3) System Functional Analyzing}

System functional analyzing needs to analyze what functions shall be included in the overall system and what roles these functions play, as well as to analyze what functions are needed to be included in "Smart Tourism" in light of administers and tourists of the scenic regions.

\section{(4) Provisions Software Performance}

Since software system is required to meet the demand of operation management of "Smart Tourism", such three criteria as the overall technical requirements of the system, time characteristics requirement, and flexibility requirement of the system shall be attained.

\section{(5) Data Management Ability}

After being established, the system needs to perform central management of the three-dimensional model data including images, topographic data, urban architecture, landscape, sketch, and vegetation, and the like. Various service information and attachment data are increasingly added in the late application for the system, and therefore the system has to be provided with corresponding capability in data management.

\section{(6) Project Budgets}

Project budgets pose a vital restraint on the development of overall project. As the construction of "Smart Tourism" needs to use a large number of electronic information equipments, the extent of development depends on the quantity of budgets.

\section{B. Development}

During the development stage, in accordance with the three stages model (Chan \& Nickerson 2007) regarding project research and development and commercialization and Project Appraisal Model (PAM) (Silverman,1981), we introduce the parameter of consumer savings (comprising two factors: project schedules, and Platform developing-based) to describe the influence factors confronted with "Smart Tourism" in the development stage and differences of these factors in the aspect of development of "Smart Tourism".

\section{Commercialization}

In the commercialization stage: in accordance with Project Appraisal Model (PAM) (Silverman 1981), we introduce the parameter of societal factors (Huchzermeier \& Loch 2001)(comprising four factors: Market payoffs, Product performance, Market requirements, and Local Government Demand). As essential contents for whether the "Smart Tourism" can be successfully operated, societal factors, particularly the Market payoffs play a critical influence. Moreover, Local Government Demand in China is also of great significance, since the investment from governments play a vital role in the construction and development of the "Smart Tourism". Taking the "Smart Tourism" in Tai Mountain and Huang Mountain for example, their commercialization is introduced. Including: (1) Market payoffs; (2) Product Performance; (3) Market requirements. 


\section{CASE ANALYSIS}

\section{A. Scenic Region Heterogeneity Case Comparison}

Situated within the territory of Tai'an city of Shandong province, Tai Mountain Natural and Cultural Heritage Conservation Area is ranked into National Key Scenic Spot in 1983 and Natural and Cultural Heritage Directory by UNESCO in 1987, and it is rated as World Geopark in 2006. Covering an area of 242 square kilometers, the scenic spot organically combines the natural landscape rich in aesthetic value and scientific value with centuries-old ethnic culture. The Mount has been honored as "the most revered one of China's five sacred mountains" since ancient times and evolves into a holy and sacred mountain of the Chinese nation, and it receives tourists approximately 4 million annually.

Huang Mountain, credited to be the King of all the mountains and one of the grand high mountains, is located in the territory of Huangshan district of Huangshan city in the southern part of An'hui province (the scenic spot is directly under the jurisdiction of the city), with east longitude being $118^{\circ} 1$ ', northern latitude being $30^{\circ} 1$, a total area being 1,078 square kilometers. Over the past year of 2012, the Huangshan city receives the tourists 36 million.

\section{B. Project Budgets Case Comparison}

“Smart Tai Mountain”: As one-time investment, the capital usage efficiency is high. The project makes a total investment of 30.22 million yuan (the original budget is 18.00 million yuan, and the actual expenditure exceeds 12.22 million yuan), among which the investment for equipment is the largest and occupies $75.9 \%$ of the total investment, including domestic and foreign network, security, video monitoring, electronic ticket, central office hardware device purchase and so on, and the test outsourcing fee occupies $14.7 \%$ of the total investment, mainly comprising expenses on system software development such as the three-dimensional GIS, and electronic ticket. The above two items accounts for $90 \%$ of the total investment of the project.

\section{System Functional Analyzing Case Comparison}

1) Relations with the overal planning and design for the project. During the process of system functional analyzing, the platform of Huang Mountain differs from that of Tai Mountain. More specifically, Huang Mountain carries out the bottom-up analysis, whereas Tai Mountain implements the top-down analysis.

Hence, with respect to the overall planning formulation, the formulating idea of Huang Mountain varies from that of Tai Mountain. More specifically, "Smart Tai Mountain" is an overall portal platform, whereas "Smart Huang Mountain" is the system platform separately established for respective operating departments according to the requirements of various operating departments presided by the Management Council of the scenic regions.

2) Relations with the platform developing-based selection. Tai Mountain differs slightly from Huang Mountain in network platform selection; however, they have great difference in the three-dimensional GIS total management system development.

3) Data management ability case comparison. Regarding data management ability, due to the platform developing-based relations caused by system functional analyzing, "Smart Tai Mountain" is superior to "Smart Huang Mountain”.

On Data management ability, "Smart Tai Mountain" is superior to "Smart Huang Mountain". The "Smart Huang Mountain" does not conduct three-dimensional special effect processing on the specific cultural and natural landscape in the scenic regions, and other business subsystems are not integrated under the platform but still at the separate operating state.

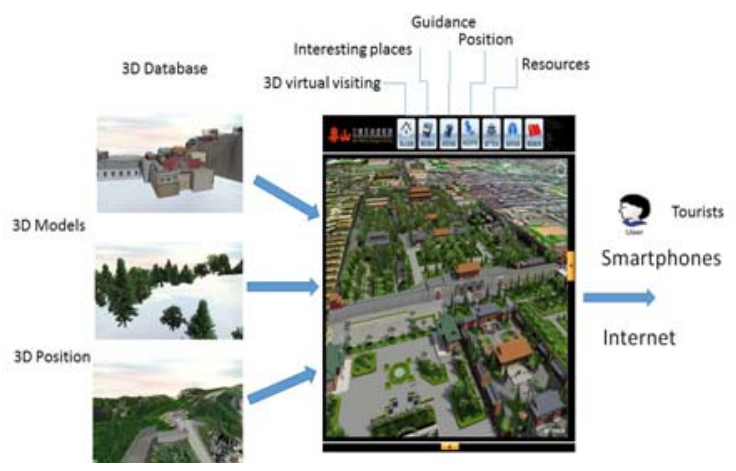

FIGURE II. EXAMPLE OF TOTAL MANAGEMENT SYSTEM FOR THREE-DIMENSIONAL TAI MOUNTAIN SMART-TOURISM

\section{Platform Developing-Based Case Comparison}

1) Relations with statistical system module for passenger flow distribution. The passenger flow system of "Smart Huang Mountain" adopts access control statistical mode, and the passenger flow distribution mainly depends on manpower, indicator and electronic broadcast persuasion.

"Smart Tai Mountain" establishes a statistical and prewarning system for passenger flow: analyzing the video images taken by a front camera; making statistics and storing the number of people going in and out from the key access points according to people's direction of motion; calculating analytical data for intelligent identification of the passangeway of the scenic spots and regions so as to obtain real-time number of passenger flow. Each of the clients uses the Web browser to inquire real-time the stream of people in each entrances. Further, the decision-making level of the scenic spots and staff may perform distributions for tourists according to people counting. 


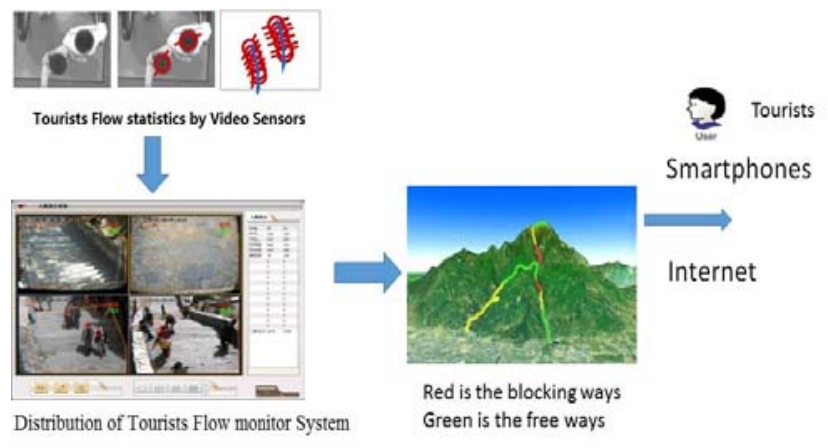

FIGURE III. STATISTICAL SYSTEM INTERFACE FOR PASSENGER FLOW DISTRIBUTION IN TAI MOUNTAIN

\section{E. COMMERCIALIZATION Case Comparison}

1) Analysis on relations with scenic region heterogeneity. In terms of Scenic Region Heterogeneity, the scenic region of Huang Mountain is superior to that of Tai Mountain, and therefore purely from the perspective of incomes, the profits of Huang Mountain are far greater than those of Tai Mountain.

Current situation of tourism for "Smart Huang Mountain": In 2012, the Huangshan city receives tourists 36 million, and the total income from tourism breaks through 30 billion yuan, among which 1,6 million are inbound tourists; foreign exchange earnings in tourism reach to 0,48 billion US dollars, and four index all increase more than 2 times compared to 5 years ago.

Current situation of tourism for "Smart Tai Mountain": Ever since the construction of "Smart Tai Mountain" in 2006, the passenger flow presents sustainable growth. The fiscal revenue of the scenic regions achieves 0,38214 billion yuan in 2010, with growing by $13.91 \%$ year on year, and fulfills $109.21 \%$ of the annual budgets.

2) With respect to acquiring the government investment. "Smart Huang Mountain": It starts information construction in 1995, and the accumulative investment capital exceeds 0, 15 billion, among which the provincial government supports 3, 5 million, and others are self-raised by the Management Council.

“Smart Tai Mountain”(Reference: Management Council of Taishan 2010,2011):The project has a total investment of 30, 22 million Yuan, among which the provincial government makes an investment of 3 million, the government of Tai'an city 8, 20 million, and other 18, 72 million are self-raised by the Management Council of the scenic spot.

\section{CONCLUSION}

Taking the three stages of R\&D project pipeline of dynamic-programming model (Chan \& Nickerson 2007) as a primary reference, as referring to Project Appraisal Model (PAM) (Silverman 1981), five example types of $R \& D$ uncertainty (Huchzermeier \& Loch 2001), and selecting the construction of "smart Tai Mountain" and "smart Huang Mountain" as cases, this study discusses how the "Smart Tourism" starts in China and how the administers of the scenic regions dynamically adjust these projects according to the respective influence factors.

\section{ACKNOWLEDGMENT}

The corresponding author is grateful for the financial support provided by National Social Science Foundation of P.R.China (13CGL103).

\section{REFERENCES}

[1] Arora A., A. Fosfuri, T. Rønde.2013.Managing Licensing in a Market for Technology. Management Science.Vol. 59, No. 5, pp. 1092-1106.

[2] Bayus B. L.2013.Crowdsourcing New Product Ideas over Time:An Analysis of the Dell IdeaStorm Community. Management Science.Vol. 59, No. 1, pp. 226-244.

[3] Caragliu, A., D.B. Chiara, P. Nijkamp.2011.Smart Cities in Europe. Journal of Urban Technology. vol. 18, Iss. 2, pp.65-82.

[4] Chan, T.,J.A. Nickerson.2007.Strategic Management of R\&D Pipelines with Cospecialized Investments and Technology Markets. Management Science.vol.53 no. 4 pp. 667-682.

[5] Chinese State Ministry of housing and urban rural development, 2008. Lushan Scenic Region Digital Planning.

[6] Creswell, J.W. Research Design: Qualitative, Quantitative, and Mixed Methods Approaches Sage Publications, Thousand Oaks, CA, 2009.

[7] Dang, A.R.,D.M. Zhang, Y. Chen.2011.Study on the Essential Concept and General Framework of Smart Famous Scenic Site. Chinese Garden. vol. 27, pp.15-19.

[8] Gaël, C.,D.R. Jérome, C. Saskia.2011.Smart travel guide: from internet image database to intelligent system. SPIE Proceedings. vol.7881, pp.110.

[9] Huchzermeier, A., C. H. Loch.2001. Project management under risk: Using the real options approach to evaluate flexibility in R\&D. Management Science. vol. 47, no.1,pp.85-101.

[10] Hung, J.C.,Y.H. Lee.2009.Constructing an Intelligent Travel Information Platform Based on Location Base Service. Pervasive Computing (JCPC).vol.3 no.5 pp.845-850.

[11] Jaraba F.B., I.L. Ruiz, M. Á. G. Nieto.NFC Solution for the Development of Smart Scenarios Supporting Tourism Applications and Surfing in Urban Environments. Trends in Applied Intelligent Systems. Volume 6098, 2010, pp 229-238.

[12] Michael, T. P.,C.H. Loch, A.D. Meyer.2002. On Uncertainty, Ambiguity, and Complexity in Project Management. Management Science. vol. 48 no. 8 pp.1008-1023.

[13] Pisano G. P. 2002. Discovering the future: R\&D Strategy at Merck.HBS Case 601-086, Harvard Business School, Boston, MA.

[14] Pavlou, P. A., D. Gefen. 2004. Building effective online marketplaces with institution-based trust. Information Systems Research, 15(1), 37-59.

[15] Rusu S., R. Cureteanu. 2009. International tourism evolution and smartphone impact on tourism. Economics and Business Research. No. 2, pp. 64-68.

[16] Sam, A.,C. Peter.2011.Creating Smart-er Cities: An Overview. Journal of Urban Technology. vol.18 lss.2 pp.1-16.

[17] Silverman, B.G.1981.Project Appraisal Methodology: A Multidimensional R\&D Benefit/Cost Assessment Tool.Management Science. vol.27, no. 7, pp.802-820.

[18] Zhang, X.P., G.P. Deng.2010. Initial Research about Smart Tourism. Chinese Tourism. vol.7 pp.1-2. 